\title{
Associations Between Dynamic Contrast Enhanced Magnetic Resonance Imaging and Clinically Relevant Histopathological Features in Breast Cancer. A Multicenter Analysis
}

\section{Alexey Surov (D Alexey.Surov@med.ovgu.de)}

Otto-von-Guericke-University Magdeburg: Otto von Guericke Universitat Magdeburg https://orcid.org/0000-00029273-3943

Maciej Pech

Otto-von-Guericke-University Magdeburg: Otto von Guericke Universitat Magdeburg

Jin You Kim

Pusan National Hospital

Marco Aiello

IRCCS SDN

Wei Huang

Advanced Imaging Research Center Oregon

Thomas E. Yankeelov

Livestrong Cancer Institutes

\section{Andreas Wienke}

Martin-Luther-Universität Halle-Wittenberg: Martin-Luther-Universitat Halle-Wittenberg

\section{Research article}

Keywords: breast cancer, DCE MRI, KI 67, hormone receptor

Posted Date: November 20th, 2020

DOI: https://doi.org/10.21203/rs.3.rs-111377/v1

License: (c) (i) This work is licensed under a Creative Commons Attribution 4.0 International License. Read Full License

Version of Record: A version of this preprint was published at In Vivo on December 30th, 2021. See the published version at https://doi.org/10.21873/invivo.12717. 


\section{Abstract}

Background: To provide evident data regarding relationships between quantitative dynamic contrast enhanced magnetic resonance imaging (DCE MRI) and prognostic factors in breast cancer (BC).

Methods: Data from 4 centers (200 female patients, mean age, $51.2 \pm 11.5$ years) were acquired. The following data were collected: histopathological diagnosis, tumor grade, stage, hormone receptor status, KI 67, and DCE MRI values including $\mathrm{K}_{\text {trans }}$ (volume transfer constant), $\mathrm{V}_{\mathrm{e}}$ (volume of the extravascular extracellular leakage space (EES) and $\mathrm{K}_{\text {ep }}$ (diffusion of contrast medium from the EES back to the plasma).

DCE MRI values between different groups were compared using the Mann-Whitney $U$ test and by the Kruskal-Wallis $\mathrm{H}$ test. The association between DCE MRI and Ki 67 values was calculated by Spearman's rank correlation coefficient.

Results: DCE MRI values of different tumor subtypes overlapped significantly. There were no statistically significant differences of DCE MRI values between different tumor grades. All DCE MRI parameters correlated with KI 67: $\mathrm{K}_{\text {trans, }} \mathrm{r}$ $=0.44, p=0.0001 ; V_{e}, r=0.34, p=0.0001 ; K_{e p}, r=0.28, p=0.002$. ROC analysis identified a $K_{\text {trans }}$ threshold of $0.3 \mathrm{~min}^{-1}$ for discrimination of tumors with low KI 67 expression (<25\%) and high $\mathrm{KI} 67$ expression ( $\geq 25 \%$ ): sensitivity, $75.5 \%$, specificity, 73.0\%, accuracy, 74.0\%, AUC, 0.78. DCE MRI values overlapped between tumors with different T and N stages.

Conclusion: $\mathrm{K}_{\text {trans, }} \mathrm{K}_{\mathrm{ep}}$, and $\mathrm{V}_{\mathrm{e}}$ cannot be used as reliable a surrogate marker for hormone receptor status, tumor stage and grade in $\mathrm{BC}$. $\mathrm{K}_{\text {trans }}$ may discriminate lesions with high and lower proliferation activity.

\section{Background}

Breast cancer (BC) is the most common noncutaneous malignancy among women, representing 4 in 10 female cancer patients in the United States [1]. Radiological imaging plays an essential role in the diagnosis and staging of BC. Moreover, imaging can also predict some clinically important histopathological features like expression of proliferation marker $\mathrm{KI} 67$ [2, 3]. So far, it has been shown that rim enhancement on dynamic magnetic resonance imaging (MRI) was associated with high expression of $\mathrm{KI} 67$ and poor prognosis of $\mathrm{BC}$ [3]. Similarly, numerous studies analyzed the role of diffusion weighted imaging (DWI) in characterization of BC [4-7]. Some authors observed statistically significant correlations between apparent diffusion coefficient and expression of KI 67 [6, 7], as well as with hormone receptor status $[8,9]$. However, it is a known phenomenon that frequently large studies do not confirm promising results of preliminary reports based on small numbers of patients/tumors. In fact, multicenter studies showed that ADC cannot reflect $\mathrm{KI} 67$ and hormone receptor expression in $\mathrm{BC}[10,11]$.

Previously, some reports also indicated that dynamic contrast enhanced MRI (DCE MRI) can be used as imaging biomarker in $\mathrm{BC}[6,12,13]$. According to the literature, quantitative parameters of DCE MRI, namely volume transfer constant $\left(\mathrm{K}_{\text {trans }}\right)$, volume of the extravascular extracellular leakage space $\left(\mathrm{V}_{\mathrm{e}}\right)$, and diffusion of contrast medium from the EES back to the plasma $\left(\mathrm{K}_{\mathrm{ep}}\right)$ reflect different histopathological features in $\mathrm{BC}[6,12,13]$. For example, Kang et al. showed that triple negative BC exhibited higher $K_{\text {trans }}$ and $K_{e p}$ in comparison to luminal cancers $(P<0.05)$ [13]. Furthermore, estrogen receptor $(E R)$ negative tumors had higher $K_{\text {trans }}$ than ER-positive tumors $(P<0.05)$ and progesterone receptor $(P R)$ negative tumors presented higher $V_{e}$ than $P R-p o s i t i v e$ tumors $(P<0.05)[13]$. Finally, 
tumors with higher $\mathrm{KI} 67$ showed higher $\mathrm{K}_{\text {ep }}$ than tumors with lower Ki-67 $(\mathrm{P}<0.05)$ [13]. Nagasaka et al. reported that the mean of $\mathrm{V}_{\mathrm{e}}$ was lower in cancers with a high $\mathrm{KI} 67$ index than in cancers with low $\mathrm{KI} 67(\mathrm{P}=0.002)$ [14].

However, other authors did not find significant associatiations between $\mathrm{V}_{\mathrm{e}}, \mathrm{K}_{\mathrm{ep}}$ and expression of $\mathrm{KI} 67$ in $\mathrm{BC}$ [15].

The purpose of the present study was to provide evident data about relationships between DCE MRI parameters and clinically relevant histopathological features in BC.

\section{Methods}

\section{Data acquisition and Patients}

The present analysis was approved by the institutional review board (Number: 36/20, Otto-von-Guericke University, Magdeburg).

For analysis of associations between imaging and histopathology in BC a multicenter work group was established $[10,11]$. For this study, the partners of our work group were contacted via email with the request to provide the data regarding DCE MRI in BC. There were the following centers:

- Medical Research Institute, Pusan National University School of Medicine, Busan, Republic of Korea and Department of Radiology, Pusan National University Hospital, Busan, Republic of Korea (center 1);

- RCCS SDN, Istituto di Ricerca, Naples, Italy (center 2);

- Advanced Imaging Research Center, Oregon Health \& Science University, Portland, OR, USA (center 3);

- Departments of Biomedical Engineering, Diagnostic Medicine, and Oncology

Livestrong Cancer Institutes Oden Institute of Computational and Engineering Sciences The University of Texas at Austin, USA (center 4).

For every case of the investigated patients/tumors the following data were collected: age, precise histopathological diagnosis, tumor grade, tumor stage, hormone receptor status, $\mathrm{KI} 67$ index, and DCE MRI values including $\mathrm{K}_{\text {trans }}$ or volume transfer constant, $\mathrm{V}_{\mathrm{e}}$ or volume of the extravascular extracellular leakage space (EES) and $\mathrm{K}_{\mathrm{ep}}$ or diffusion of contrast medium from the EES back to the plasma.

The acquired sample comprises 200 patients (Table 1). In every case, breast MRI was performed on a clinical scanner with dedicated breast radiofrequency coil. MR scanners and imaging protocols varied across the centers. 
Table 1

Data regarding patients acquisition and technical details of breast DCE MRI in the involved centers

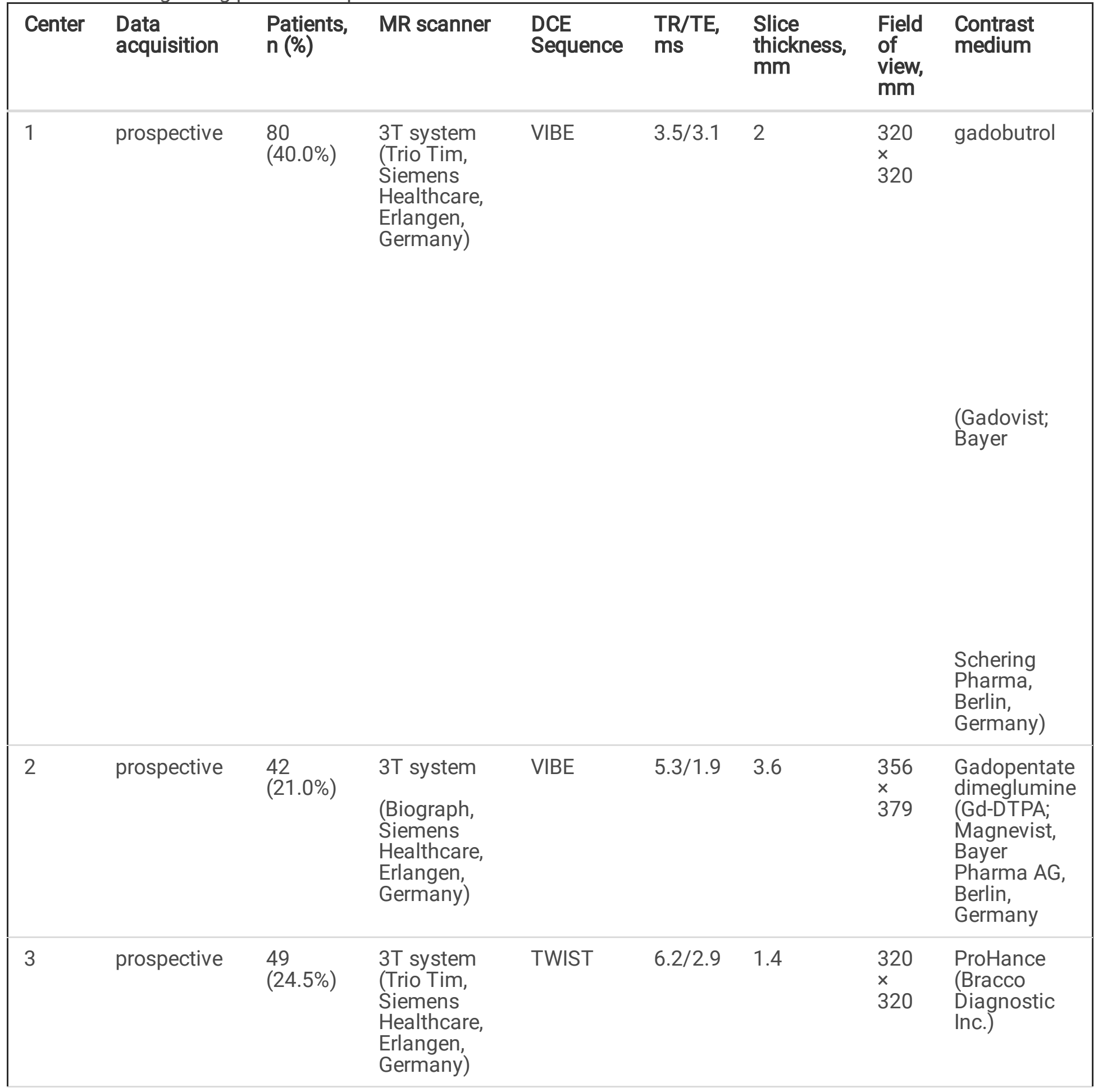

VIBE, Volumetric Interpolated Breath-hold Examination

TWIST, Time-resolved angiography WIth Stochastic Trajectories;

$\mathrm{RF}$, radio frequency 


\begin{tabular}{|c|c|c|c|c|c|c|c|c|}
\hline Center & $\begin{array}{l}\text { Data } \\
\text { acquisition }\end{array}$ & $\begin{array}{l}\text { Patients, } \\
\text { n (\%) }\end{array}$ & MR scanner & $\begin{array}{l}\text { DCE } \\
\text { Sequence }\end{array}$ & $\begin{array}{l}\text { TR/TE, } \\
\text { ms }\end{array}$ & $\begin{array}{l}\text { Slice } \\
\text { thickness, } \\
\text { mm }\end{array}$ & $\begin{array}{l}\text { Field } \\
\text { of } \\
\text { view, } \\
\mathrm{mm}\end{array}$ & $\begin{array}{l}\text { Contrast } \\
\text { medium }\end{array}$ \\
\hline 4 & retrospective & $\begin{array}{l}29 \\
(14.5 \%)\end{array}$ & $\begin{array}{l}\text { Philips 3T } \\
\text { Achieva MR } \\
\text { scanner } \\
\text { (Philips } \\
\text { Healthcare, } \\
\text { Best, The } \\
\text { Netherlands) }\end{array}$ & $\begin{array}{l}\text { RF- } \\
\text { spoiled } \\
\text { 3D } \\
\text { gradient } \\
\text { echo }\end{array}$ & 7.9/1.3 & 5 & $\begin{array}{l}220 \\
\times \\
220\end{array}$ & $\begin{array}{l}\text { Gadopentate } \\
\text { dimeglumine } \\
\text { (Gd-DTPA; } \\
\text { Magnevist } \\
\text { Wayne, NJ }\end{array}$ \\
\hline \multicolumn{9}{|c|}{ VIBE, Volumetric Interpolated Breath-hold Examination } \\
\hline \multicolumn{9}{|c|}{ TWIST, Time-resolved angiography WIth Stochastic Trajectories; } \\
\hline \multicolumn{9}{|c|}{$\mathrm{RF}$, radio frequency } \\
\hline
\end{tabular}

\section{Statistical analysis}

Continuous variables were described by mean value and standard deviation. Categorical variables were given as relative frequencies. The comparison of DCE MRI values in groups was performed by Mann-Whitney-U tests where the $\mathrm{p}$-values are adjusted for multiple testing (Bonferroni correction). The association between DCE MRI values and $\mathrm{KI} 67$ values was calculated by Spearman's rank correlation coefficient. Sensitivity, specificity, negative and positive predictive values, accuracy, and area under the receiver operating characteristic curve (AUC) value were calculated for the diagnostic procedures. Thresholds are chosen to maximize the Youden index.

\section{Results}

A total of 200 female patients, mean age, $51.2 \pm 11.5$ years was acquired for this study. The patients had a variety of different breast tumor histologic types (Table 2). The majority of tumors were invasive ductal carcinoma (IDC, $81.95 \%$ ) with a limited number of other histopathological subypes. 
Table 2

Tumor subtypes

\begin{tabular}{|c|c|}
\hline Subtype & $\mathrm{n}(\%)$ \\
\hline Invasive ductal carcinoma & $167(83.5)$ \\
\hline Invasive lobular carcinoma & $6(3.0)$ \\
\hline Mucinous breast cancer & $3(1.5)$ \\
\hline No special type & $24(12.0)$ \\
\hline \multicolumn{2}{|l|}{ Receptor status } \\
\hline Luminal A & $49(24.5)$ \\
\hline Luminal B & $84(42.0)$ \\
\hline HER 2+ & $32(16.0)$ \\
\hline Triple negative & $19(9.5)$ \\
\hline Not available & $16(8.0)$ \\
\hline \multicolumn{2}{|l|}{ Tumor grade } \\
\hline 1 & $25(12.5)$ \\
\hline 2 & $96(48.0)$ \\
\hline 3 & 79 (39.5) \\
\hline \multicolumn{2}{|l|}{ T stage } \\
\hline 1 & $73(36.5)$ \\
\hline 2 & $78(39.0)$ \\
\hline 3 & $22(11.0)$ \\
\hline 4 & 27 (13.5) \\
\hline \multicolumn{2}{|l|}{ N stage } \\
\hline 0 & $104(52.0)$ \\
\hline 1 & $51(25.5)$ \\
\hline 2 & $22(11.0)$ \\
\hline 3 & $23(11.5)$ \\
\hline \multicolumn{2}{|l|}{ M stage } \\
\hline 0 & $186(93.0)$ \\
\hline 1 & $14(7.0)$ \\
\hline
\end{tabular}

The DCE MRI values $(M \pm S D)$ of the tumors were as follows: $K_{\text {trans, }} 0.33 \pm 0.65$ min $^{-1} ; V_{e}, 0.48 \pm 0.41 \% ; K_{e p}, 0.60 \pm$ $0.60 \mathrm{~min}^{-1}$. 
Hormone receptor status was available for 184 cases. Most frequently, luminal B cancers was diagnosed (Table 3). DCE MRI values in different BC subtypes are given in Table 4. Triple negative cancers had highest $\mathrm{K}_{\text {trans }}$ values, luminal $B$ cancers had highest $K_{e p}$ and $V_{e}$ values, and HER $2+B C$ had lowest $K_{\text {trans }}$ and $V_{e}$ values. There were no significant differences between $\mathrm{K}_{\text {trans }}$ and $\mathrm{K}_{\text {ep }}$ values in the $\mathrm{BC}$ subtypes. $\mathrm{V}_{\mathrm{e}}$ values were different among the tumors with several receptor expressions $(p=0.003)$. However, all DCE MRI values of different tumor subtypes overlapped significantly (Fig. 1).

Table 3

DCE MRI values in $\mathrm{BC}$ with different hormone receptor status

\begin{tabular}{|llllll|}
\hline & Luminal A cancer & Luminal B cancer & HER 2 + cancer & Triple negative cancer & P values \\
\hline $\mathrm{K}_{\mathrm{trans}}$ min $^{-1}$ & $0.24 \pm 0.27$ & $0.44 \pm 0.44$ & $0.22 \pm 0.50$ & $0.53 \pm 1.71$ & 0.161 \\
\hline $\mathrm{V}_{\mathrm{e}} \%$ & $0.50 \pm 0.43$ & $0.61 \pm 0.43$ & $0.30 \pm 0.23$ & $0.44 \pm 0.44$ & 0.003 \\
\hline $\mathrm{K}_{\mathrm{ep}}, \mathrm{min}^{-1}$ & $0.47 \pm 0.31$ & $0.72 \pm 0.53$ & $0.56 \pm 0.58$ & $0.62 \pm 1.33$ & 0.159 \\
\hline
\end{tabular}

Table 4

DCE MRI values in BC with different tumor grades

\begin{tabular}{|lllll|}
\hline & Grade 1 & Grade 2 & Grade 3 & P values \\
\hline $\mathrm{K}_{\text {trans, }} \min ^{-1}$ & $0.12 \pm 0.10$ & $0.32 \pm 0.44$ & $0.42 \pm 0.90$ & 0.135 \\
\hline $\mathbf{V}_{\mathrm{e}, \%}$ & $0.35 \pm 0.29$ & $0.49 \pm 0.39$ & $0.52 \pm 0.46$ & 0.225 \\
\hline $\mathrm{K}_{\mathrm{ep}}, \min ^{-1}$ & $0.34 \pm 0.16$ & $0.60 \pm 0.54$ & $0.67 \pm 0.75$ & 0.064 \\
\hline
\end{tabular}

\section{DCE MRI parameters and tumor grade}

DCE MRI values in different tumor grades are given in Table 4. All DCE MRI values increased with tumor grade. However, there were no significant differences of DCE MRI values between several tumor grades and all DCE MRI values of different tumor types overlapped significantly (Fig. 2).

\section{DCE MRI values and expression of KI 67}

The level of the proliferation index $\mathrm{KI} 67$ was available for 123 tumors. The mean value was $27.4 \pm 23.6 \%$, median value, $20 \%$, range $1 \%-90 \%$.

All DCE MRI parameters correlated with KI 67. The correlation coefficients were as follows: $K_{\text {trans }}, r=0.44, p=0.0001$; $V_{e}, r=0.34, p=0.0001 ; K_{e p}, r=0.28, p=0.002$.

On the next step, ROC analysis was performed for distinguishing tumors with high proliferative potential from tumors with low proliferation rate using DCE MRI values. A KI 67 value of $25 \%$ was used as the threshold in discrimination between tumors with low KI 67 expression (<25\%) and high KI 67 expression ( $\geq 25 \%$ ). Youden index 
identified threshold values of $\mathrm{K}_{\text {trans, }} \mathrm{V}_{\mathrm{e}}$, and $\mathrm{K}_{\mathrm{ep}}$ (Table 5). $\mathrm{K}_{\text {trans }}$ cut-off value of $0.3 \mathrm{~min}^{-1}$ showed best results (Fig. 3). Furthermore, other threshold values of KI 67 ranging from 10-50\% were also analyzed (Table 6). DCE MRI values had low area under the curve for every $\mathrm{KI} 67$ thresholds.

Table 5

Threshold values of $\mathrm{K}_{\text {trans, }}, \mathrm{V}_{\mathrm{e}}$, and $\mathrm{K}_{\mathrm{ep}}$ for discrimination of tumors with high (>25\%) expression of $\mathrm{KI} 67$

\begin{tabular}{|lllllll|}
\hline & Threshold & Sensitivity & Specificity & PPV & NPV & Accuracy \\
\hline $\mathrm{K}_{\mathrm{trans}}$ & 0.3 & $75.5 \%$ & $73.0 \%$ & $64.9 \%$ & $81.8 \%$ & $74.0 \%$ \\
$\mathrm{~min}^{-1}$ & & & & & & \\
\hline $\mathbf{V}_{\mathrm{e}} \%$ & 0.5 & $73.5 \%$ & $66.2 \%$ & $59.0 \%$ & $79.0 \%$ & $69.1 \%$ \\
\hline $\mathrm{K}_{\mathrm{ep}}, \min ^{-1}$ & 0.55 & $63.3 \%$ & $63.5 \%$ & $53.4 \%$ & $72.3 \%$ & $63.4 \%$ \\
\hline
\end{tabular}

Table 6

Areas under the curve for discrimination of tumors with different expression of KI 67 based on DCE MRI values

\begin{tabular}{|llllll|}
\hline \multicolumn{7}{|c|}{ KI 67 level } & & & \\
\hline & $\geq 10 \%$ & $\geq 20 \%$ & $\geq 30 \%$ & $\geq 40 \%$ & $\geq 50 \%$ \\
\hline$K_{\text {trans }}$ & 0.72 & 0.77 & 0.70 & 0.74 & 0.68 \\
\hline $\mathrm{V}_{\text {e }}$ & 0.67 & 0.73 & 0.64 & 0.63 & 0.55 \\
\hline $\mathrm{K}_{\text {ep }}$ & 0.63 & 0.67 & 0.67 & 0.72 & 0.70 \\
\hline
\end{tabular}

\section{DCE MRI parameters and T stage}

DCE MRI values differed significantly among the tumors with different T stages (Table 7). Carcinomas with T4 stage showed highest DCE MRI values in comparison to other tumor stages. However, DCE MRI values overlapped between the subgroups (Fig. 4).

Table 7

DCE MRI values in BC with different tumor $(T)$ stages

\begin{tabular}{|llllll|}
\hline & $\mathrm{T} 1$ & $\mathrm{T2}$ & $\mathrm{T3}$ & $\mathrm{T4}$ & P values \\
\hline $\mathrm{K}_{\text {trans, }} \mathrm{min}^{-1}$ & $0.18 \pm 0.13$ & $0.27 \pm 0.37$ & $0.14 \pm 0.17$ & $1.08 \pm 1.44$ & 0.001 \\
\hline $\mathrm{V}_{\mathrm{e}} \%$ & $0.37 \pm 0.19$ & $0.44 \pm 0.39$ & $0.36 \pm 0.33$ & $0.99 \pm 0.57$ & 0.001 \\
\hline $\mathrm{K}_{\text {ep }} \mathrm{min}^{-1}$ & $0.50 \pm 0.29$ & $0.54 \pm 0.41$ & $0.36 \pm 0.23$ & $1.21 \pm 1.26$ & 0.001 \\
\hline
\end{tabular}




\section{DCE MRI parameters and nodal tumor stage}

Overall, in 104 BC N0 and in 96 BC N + stages were diagnosed. All DCE MRI values were statistically significant higher in $\mathrm{N}+$ tumors than in N0 lesions (Table 8). However, the graphical distribution of DCE MRI values showed that they overlapped between the subgroups (Fig. 5). Furthermore, ROC analysis also showed that DCE MRI values had very low areas under the curve in prediction of nodal stage in BC (Fig. 6).

Table 8

Comparison of DCE MRI values in BC with and without nodal metastases

\begin{tabular}{|llll|}
\hline & BC with N0 stage, $\mathrm{M} \pm \mathrm{SD}$ & $\begin{array}{l}\text { BC with } \mathrm{N}+\text { stage, } \\
\mathrm{M} \pm \mathrm{SD}\end{array}$ & P values \\
\hline $\mathrm{K}_{\text {trans, }} \min ^{-1}$ & $0.17 \pm 0.15$ & $0.50 \pm 0.89$ & 0.001 \\
\hline $\mathrm{V}_{\mathrm{e}} \%$ & $0.37 \pm 0.21$ & $0.60 \pm 0.52$ & 0.001 \\
\hline $\mathrm{K}_{\mathrm{ep}}, \min ^{-1}$ & $0.48 \pm 0.34$ & $0.72 \pm 0.79$ & 0.007 \\
\hline
\end{tabular}

\section{Discussion}

The present study is the first multicenter project regarding associations between DCE MRI and clinically relevant histopathological features in BC.

Previously, the role of DCE MRI was analyzed systematically in prostate cancer, glioma, and squamous cell carcinoma of the head and neck region. In prostate cancer, it was shown that $\mathrm{K}_{\text {trans }}$ values were significantly higher for high-grade versus low-grade lesions [16]. Furthermore, $\mathrm{K}_{\mathrm{ep}}$ correlated positively with mean blood vessel count and mean vessel area [17]. In glioma, $\mathrm{K}_{\text {trans }}$ and $\mathrm{V}_{\mathrm{e}}$ values of grade 2 tumors were significantly lower than those of grade 3 [18]. Moreover, $\mathrm{K}_{\text {trans }}$ and $\mathrm{V}_{\mathrm{e}}$ significantly correlated with the $\mathrm{KI} 67$ index [18]. Finally, $\mathrm{K}_{\text {trans }}$ showed a significant positive correlation with VEGF expression in high grade gliomas $(r=0.505, P<0.001)$ [19]. Also in head and neck squamous cell carcinomas DCE MRI can predict relevant histopathological features. So far, $\mathrm{K}_{\text {trans }}$ correlated well with expression of $\mathrm{Ki} 67$ and $\mathrm{V}_{\mathrm{e}}$ with the mean microvessel diameter [20].

In BC, only few studies reported data about associations between DCE MRI and histopathology. The published results are promising. For instance, it has been shown that parameters of DCE MRI were different in tumors with different hormone receptor expression and grade. So far, grade 3 cancers had higher $\mathrm{K}_{\text {trans }}$ and $\mathrm{K}_{\mathrm{ep}}$ values in comparison to grade 1 lesions $[12,13]$. Mean $\mathrm{V}_{\mathrm{e}}$ was lower in tumors with a high histologic grade than in tumors with a low histologic grade [12]. Regarding expression of hormone receptors, triple negative BC showed higher $\mathrm{K}_{\text {trans }}$ and $\mathrm{K}_{\mathrm{ep}}$, but lower $\mathrm{V}_{\mathrm{e}}$ values than luminal $\mathrm{BC}$ [13]. Furthermore, Ve correlated inversely with HER 2 expression [21].

Our data showed that HER 2 rich $\mathrm{BC}$ had lowest $\mathrm{K}_{\text {trans }}$ and $\mathrm{V}_{\mathrm{e}}$ values in comparison to other subtypes. Furthermore, triple negative $\mathrm{BC}$ had highest $\mathrm{K}_{\text {trans }}$ values. However, as shown, values of DCE MRI overlapped significantly and, therefore, cannot be used for prediction of hormone receptor status in $\mathrm{BC}$ in clinical practice.

Furthermore, our data indicated that DCE MRI parameters did not reflect tumor grade in BC. 
Another important aspect in $\mathrm{BC}$ is expression of proliferation marker $\mathrm{KI} 67$. It is well known that high expression of $\mathrm{KI}$ 67 is associated with a greater risk of death compared with lower expression rates [22]. Therefore, prediction of proliferation potential of $\mathrm{BC}$ based on imaging is very important. According to previous reports, parameters of DCE MRI are associated with KI 67 index. However, the reported data are controversial $[12,13,21,23]$. For example, Kang et al. showed that carcinomas with high expression KI 67 showed statistically significant higher Kep values in comparison to $\mathrm{BC}$ with low expression of $\mathrm{KI} 67$ and $\mathrm{K}_{\text {trans }}$ and $\mathrm{V}_{\mathrm{e}}$ values did not differ between the tumors [13]. Liu et al. found that only $\mathrm{K}_{\text {trans }}$ correlated with $\mathrm{KI} 67$ [21]. Koo et al. did not observed statistically significant associations between DCE MRI values and KI 67 [12]. Finally, Kim et al. observed significant relationships between $\mathrm{K}_{\text {trans, }}, \mathrm{K}_{\mathrm{ep}}$ and $\mathrm{KI} 67$, but not between $\mathrm{V}_{\mathrm{e}}$ and $\mathrm{KI} 67$ [23]. Moreover, the previous studies used different thresholds of $\mathrm{KI} 67$ expression for distinguishing tumors with low and high proliferation activity, namely $15 \%$ [13], 10\% [21], and 5\% [12]. In one study two threshold values, $5 \%$ and $15 \%$ were analyzed [23]. This fact relativizes the reported results. According to a large meta analysis based on data of 64,196 patients, the optimal KI 67 cut-off is $25 \%$ [22].

In the present work, $\mathrm{KI} 67$ correlated statistically significant with all DCE MRI parameters. The strongest correlation was observed with $\mathrm{K}_{\text {trans }}(r=0.44, \mathrm{p}=0.0001)$. However, the optimal threshold of $\mathrm{K}_{\text {trans }}$ to discriminate $\mathrm{BC}$ with high $(>25 \%)$ and low (<25\%) expression of $\mathrm{KI} 67$ yielded a relatively low sensitivity $(75.5 \%)$ and specificity (73.0\%), as well as low accuracy (74.0\%). Also, this applied for several alternate thresholds of KI 67 expression ranging from $10-50 \%$.

Another important clinical question is, if imaging features of primary tumors can predict occurrence of nodal and/or distant metastases. Previously, it has been indicated that some MRI features of BC were associated with occurrence of nodal metastases [24]. Regarding DCE MRI, presumably, perfusion parameters of primary tumor may be able to predict occurrence of lymph node metastases. In fact, BC with lymphovascular space invasion (LVSI) had higher $\mathrm{K}_{\text {trans }}$ and $\mathrm{K}_{\mathrm{ep}}$ than tumors without LVSI [13]. Our results, however, did not confirm this hypothesis. Although DCE MRI parameters of BC differed between NO vs $\mathrm{N}+$ stages, all of them overlapped significantly. Therefore, parameters of DCE MRI obtained from primary tumors cannot be used for prediction of nodal stage in BC.

The present multicenter study is the largest to date. However, there are some limitations to address. The involved patients were investigated on different MR scanners with different technical parameters like field strength and other technical parameters. Furthermore, one center acquired patients with BC retrospectively with appropriate bias. Our sample consist predominantly on invasive ductal carcinomas. Therefore, this study could not compare DCE MRI values between different tumor types. Presumably, other types like lobular or mucinous carcinomas may have different DCE MRI parameters than ductal carcinomas.

\section{Conclusions}

Our multicenter study showed that DCE MRI parameters $\mathrm{K}_{t r a n s}, \mathrm{~K}_{\mathrm{ep}}$, and $\mathrm{V}_{\mathrm{e}}$ cannot be used as reliable a surrogate marker for hormone receptor status, tumor stage and grade in $\mathrm{BC}$. $\mathrm{K}_{\text {trans }}$ correlated moderately with expression of $\mathrm{KI}$ 67 and may discriminate lesions with high and lower proliferation activity.

\section{Abbreviations}

$\mathrm{BC}$, breast cancer

DCE MRI, dynamic contrast enhanced magnetic resonance imaging 
$\mathrm{K}_{\text {trans, }}$ volume transfer constant;

$\mathrm{V}_{\mathrm{e}}$, volume of the extravascular extracellular leakage space;

$\mathrm{K}_{\mathrm{ep}}$, diffusion of contrast medium from the extravascular extracellular leakage space back to the plasma

\section{Declarations}

\section{Ethics approval and consent to participate}

The study protocol was approved by the Ethics Committee of the Medical Faculty of the Otto-von-Guericke-University Magdeburg.

\section{Funding}

None

\section{Availability of data and materials}

The data that support the findings of this study are available from professor Surov but restrictions apply to the availability of these data, which were used under license for the current study, and so are not publicly available. Data are however available from the authors upon reasonable request and with permission of professor Surov.

\section{Consent for publication}

Not applicable

\section{Competing interests}

The authors declare that they have no competing interests

\section{Acknowledgements}

none

\section{References}

1. DeSantis CE, Lin CC, Mariotto AB, Siegel RL, Stein KD, Kramer JL, Alteri R, Robbins AS, Jemal A. Cancer treatment and survivorship statistics, 2014. CA Cancer J Clin. 2014;64:252-71

2. Youk JH, Son EJ, Chung J, Kim JA, Kim EK. Triple-negative invasive breast cancer on dynamic contrastenhanced and diffusion-weighted MR imaging: comparison with other breast cancer subtypes. Eur Radiol. 2012;22:1724-34.

3. Szabo BK, Aspelin P, Kristoffersen Wiberg M, Tot T, Bone B. Invasive breast cancer: correlation of dynamic MR features with prognostic factors. Eur Radiol. 2003;13:2425-35

4. Suo S, Cheng F, Cao M, Kang J, Wang M, Hua J, Hua X, Li L, Lu Q, Liu J, Xu J. Multiparametric diffusionweighted imaging in breast lesions: Association with pathologic diagnosis and prognostic factors. J Magn Reson Imaging. 2017;46(3):740-50. 
5. Jeh SK, Kim SH, Kim HS, Kang BJ, Jeong SH, Yim HW, Song BJ. Correlation of the apparent diffusion coefficient value and dynamic magnetic resonance imaging findings with prognostic factors in invasive ductal carcinoma. J Magn Reson Imaging. 2011;33(1):102-9.

6. Mori N, Ota H, Mugikura S, Takasawa C, Ishida T, Watanabe G, Tada H, Watanabe M, Takase K, Takahashi S. Luminal-type breast cancer: correlation of apparent diffusion coefficients with the Ki-67 labeling index. Radiology. 2015;274(1):66-73

7. Kato F, Kudo K, Yamashita H, Wang J, Hosoda M, Hatanaka KC, Mimura R, Oyama-Manabe N, Shirato H. Differences in morphological features and minimum apparent diffusion coefficient values among breast cancer subtypes using 3-tesla MRI. Eur J Radiol. 2016;85(1):96-102.

8. Sharma U, Sah RG, Agarwal K, Parshad R, Seenu V, Mathur SR, Hari S, Jagannathan NR. Potential of DiffusionWeighted Imaging in the Characterization of Malignant, Benign, and Healthy Breast Tissues and Molecular Subtypes of Breast Cancer. Front Oncol. 2016 May 23;6:126

9. Surov A, Clauser P, Chang YW, Li L, Martincich L, Partridge SC, Kim JY, Meyer HJ, Wienke A. Can diffusionweighted imaging predict tumor grade and expression of $\mathrm{Ki}-67$ in breast cancer? A multicenter analysis. Breast Cancer Res. 2018;20(1):58.

10. Surov A, Chang YW, Li L, Martincich L, Partridge SC, Kim JY, Wienke A. Apparent diffusion coefficient cannot predict molecular subtype and lymph node metastases in invasive breast cancer: a multicenter analysis. BMC Cancer. 2019;19(1):1043.

11. Koo HR, Cho N, Song IC, Kim H, Chang JM, Yi A, Yun BL, Moon WK. Correlation of perfusion parameters on dynamic contrast-enhanced MRI with prognostic factors and subtypes of breast cancers. J Magn Reson Imaging. 2012;36(1):145-51.

12. Kang SR, Kim HW, Kim HS. Evaluating the Relationship Between Dynamic Contrast-Enhanced MRI (DCE-MRI) Parameters and Pathological Characteristics in Breast Cancer. J Magn Reson Imaging. 2020 Jun 10. doi: 10.1002/jmri.27241

13. Nagasaka K, Satake H, Ishigaki S, Kawai H, Naganawa S. Histogram analysis of quantitative pharmacokinetic parameters on DCE-MRI: correlations with prognostic factors and molecular subtypes in breast cancer. Breast Cancer. 2019 Jan;26(1):113-124.

14. Shin JK, Kim JY. Dynamic contrast-enhanced and diffusion-weighted MRI of estrogen receptor-positive invasive breast cancers: Associations between quantitative MR parameters and Ki-67 proliferation status. J Magn Reson Imaging. 2017;45(1):94-102.

15. Afshari Mirak S, Mohammadian Bajgiran A, Sung K, Asvadi NH, Markovic D, Felker ER, Lu D, Sisk A, Reiter RE, Raman SS. Dynamic contrast-enhanced (DCE) MR imaging: the role of qualitative and quantitative parameters for evaluating prostate tumors stratified by Gleason score and PI-RADS v2. Abdom Radiol (NY). 2020;45(7):2225-2234.

16. Oto A, Yang C, Kayhan A, Tretiakova M, Antic T, Schmid-Tannwald C, Eggener S, Karczmar GS, Stadler WM. Diffusion-weighted and dynamic contrast-enhanced MRI of prostate cancer: correlation of quantitative MR parameters with Gleason score and tumor angiogenesis. AJR Am J Roentgenol. 2011;197(6):1382-90.

17. Jiang JS, Hua Y, Zhou XJ, Shen DD, Shi JL, Ge M, Geng QN, Jia ZZ. Quantitative Assessment of Tumor Cell Proliferation in Brain Gliomas with Dynamic Contrast-Enhanced MRI. Acad Radiol. 2019;26(9):1215-1221.

18. Di N, Cheng W, Jiang X, Liu X, Zhou J, Xie Q, Chu Z, Chen H, Wang B. Can dynamic contrast-enhanced MRI evaluate VEGF expression in brain glioma? An MRI-guided stereotactic biopsy study. J Neuroradiol. 2019;46(3):186-192. 
19. Surov A, Meyer HJ, Gawlitza M, Höhn AK, Boehm A, Kahn T, Stumpp P. Correlations Between DCE MRI and Histopathological Parameters in Head and Neck Squamous Cell Carcinoma. Transl Oncol. 2017;10(1):17-21.

20. Liu F, Wang M, Li H. Role of perfusion parameters on DCE-MRI and ADC values on DWMRI for invasive ductal carcinoma at 3.0 Tesla. World J Surg Oncol. 2018;16(1):239.

21. Petrelli F, Viale G, Cabiddu M, Barni S. Prognostic value of different cut-off levels of Ki- 67 in breast cancer: a systematic review and meta-analysis of 64,196 patients. Breast Cancer Res Treat. 2015;153(3):477-91

22. Kim JY, Kim SH, Kim YJ, Kang BJ, An YY, Lee AW, Song BJ, Park YS, Lee HB. Enhancement parameters on dynamic contrast enhanced breast MRI: do they correlate with prognostic factors and subtypes of breast cancers? Magn Reson Imaging. 2015;33(1):72-80.

23. Carbonaro LA. Can we use MR-mammography to predict nodal status? Eur J Radiol. 2012;81 Suppl 1:S17-8.

\section{Figures}
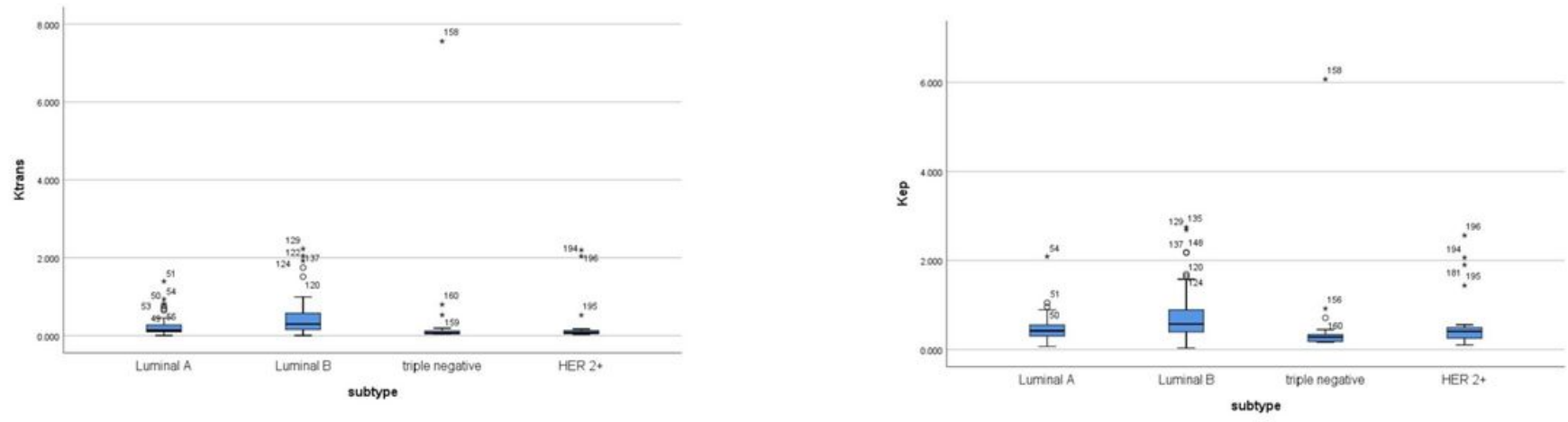

1a

$1 \mathrm{c}$

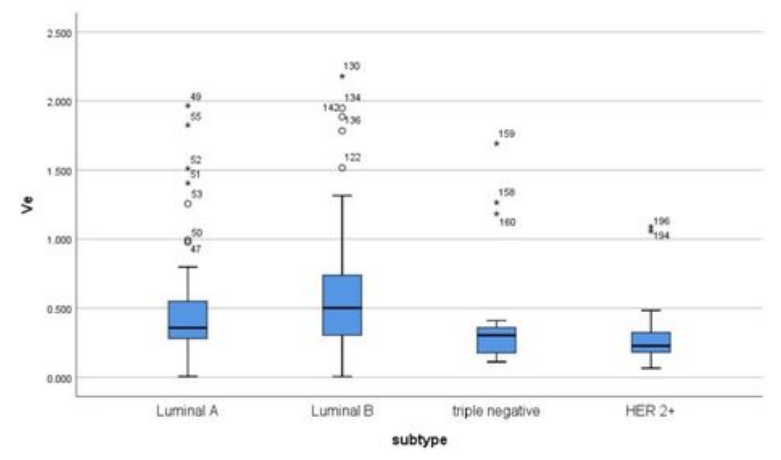

$1 b$

\section{Figure 1}

Box plots of DCE MRI values in tumors with different molecular subtypes. a. Ktrans b. Ve c. Kep 


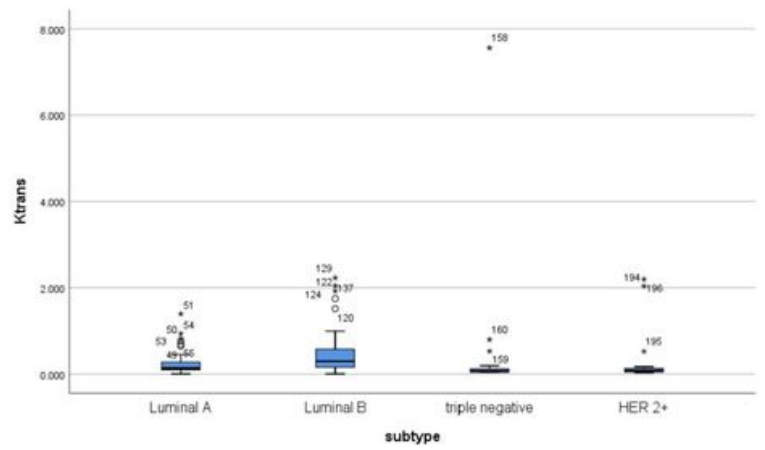

1a

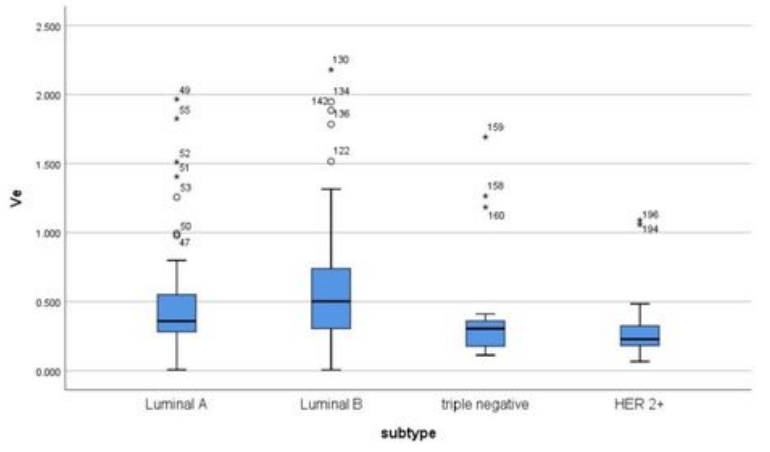

$1 b$

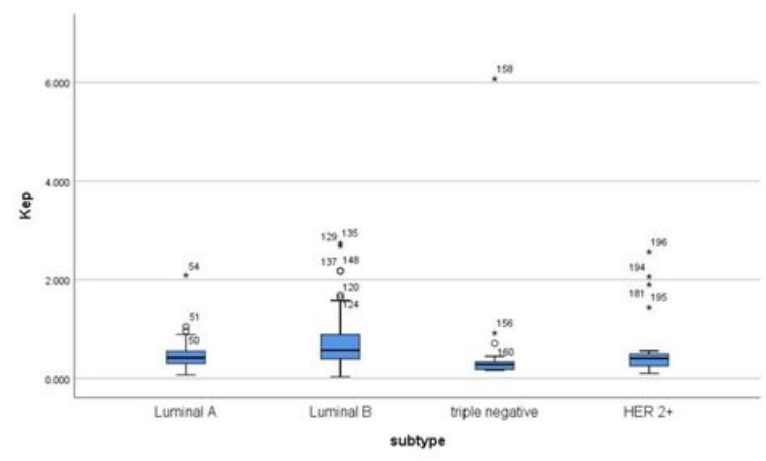

$1 c$

\section{Figure 1}

Box plots of DCE MRI values in tumors with different molecular subtypes. a. Ktrans b. Ve c. Kep 


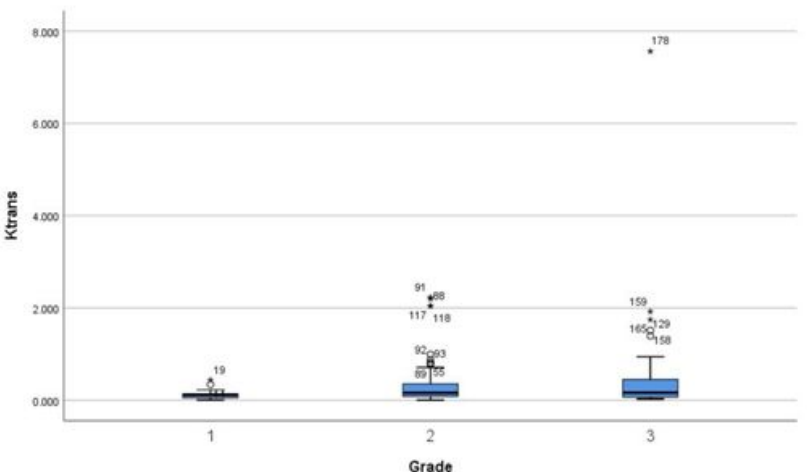

$2 a$

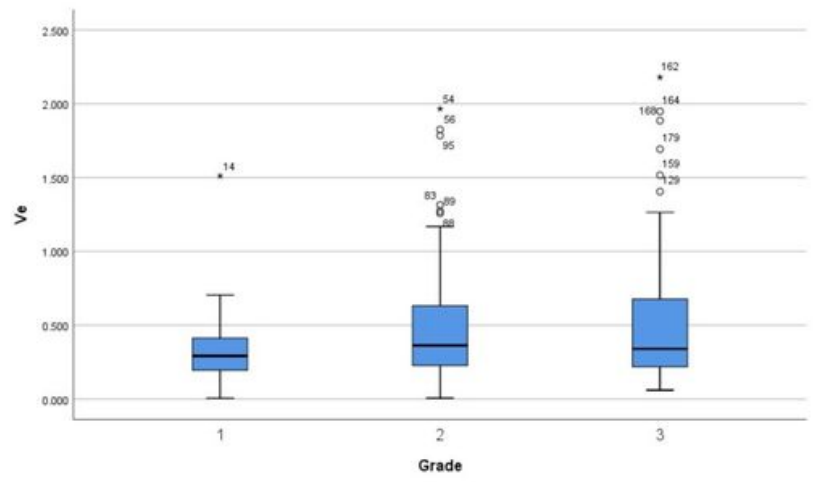

$2 b$

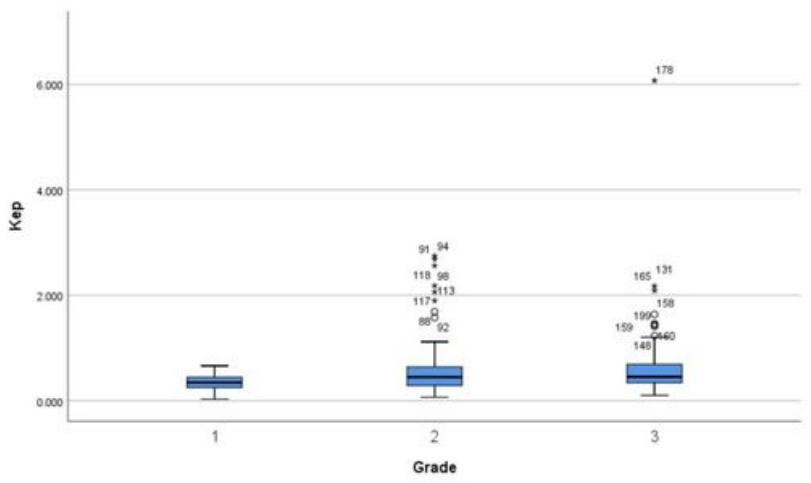

2c

\section{Figure 2}

Box plots of DCE MRI values in carcinomas with different tumor grades. a. Ktrans b. Ve c. Kep 


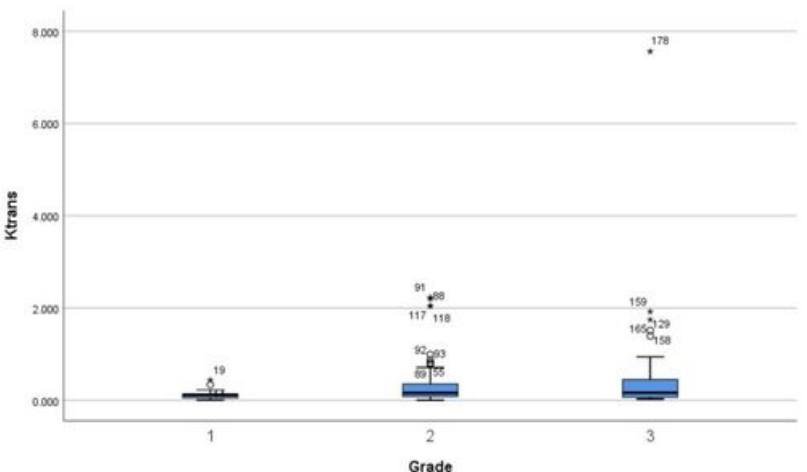

$2 a$

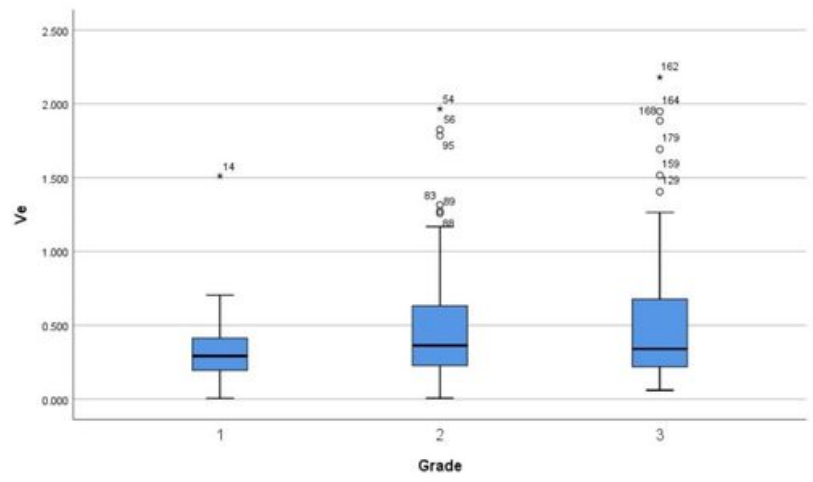

$2 b$

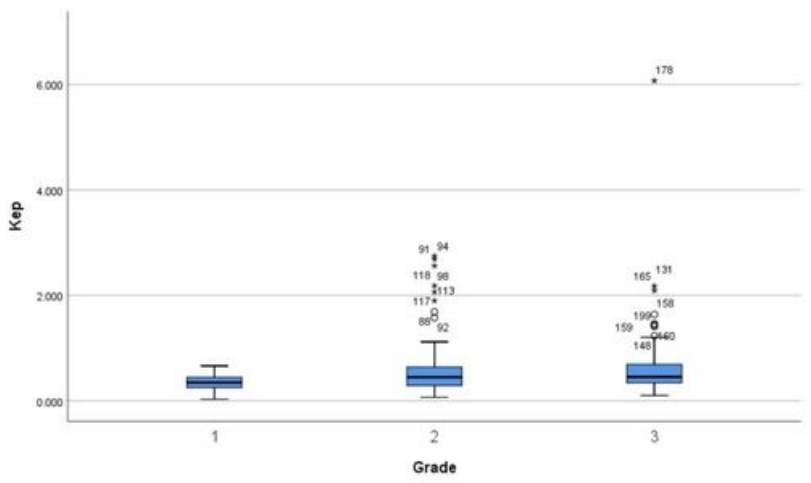

2c

\section{Figure 2}

Box plots of DCE MRI values in carcinomas with different tumor grades. a. Ktrans b. Ve c. Kep 


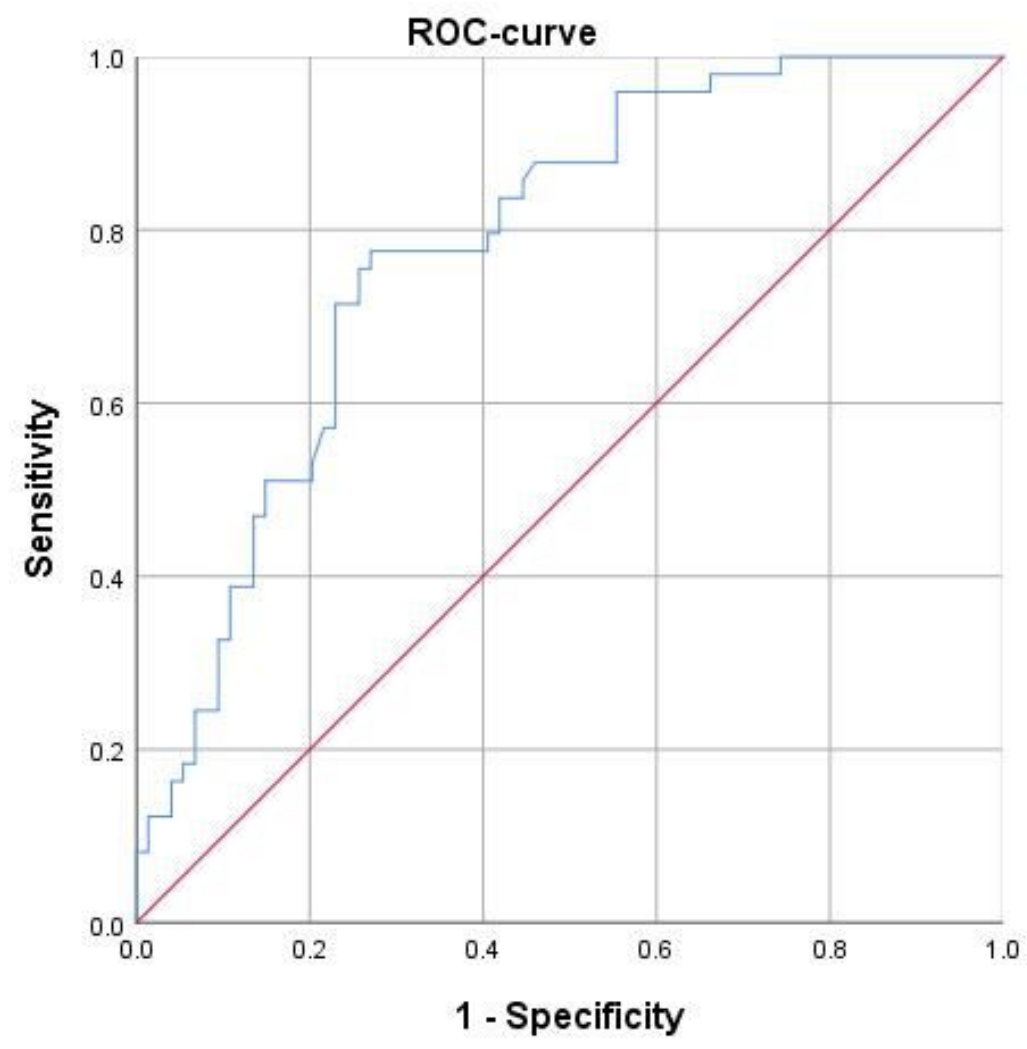

\section{Figure 3}

Receiver operating characteristic (ROC) curve for use of Ktrans for distinguishing of carcinomas with high proliferation potential (Ki67 >25\%) from tumors with low Ki 67 level $(<25 \%)$. The area under the curve is 0.78 . The optimal threshold value is $0.3 \mathrm{~min}-1$ yealding a sensitivity of $75.5 \%$, a specificity of $73.0 \%$, an accuracy of $74.0 \%$. The positive predictive value is $64.9 \%$, and the negative predictive value is $81.8 \%$. 


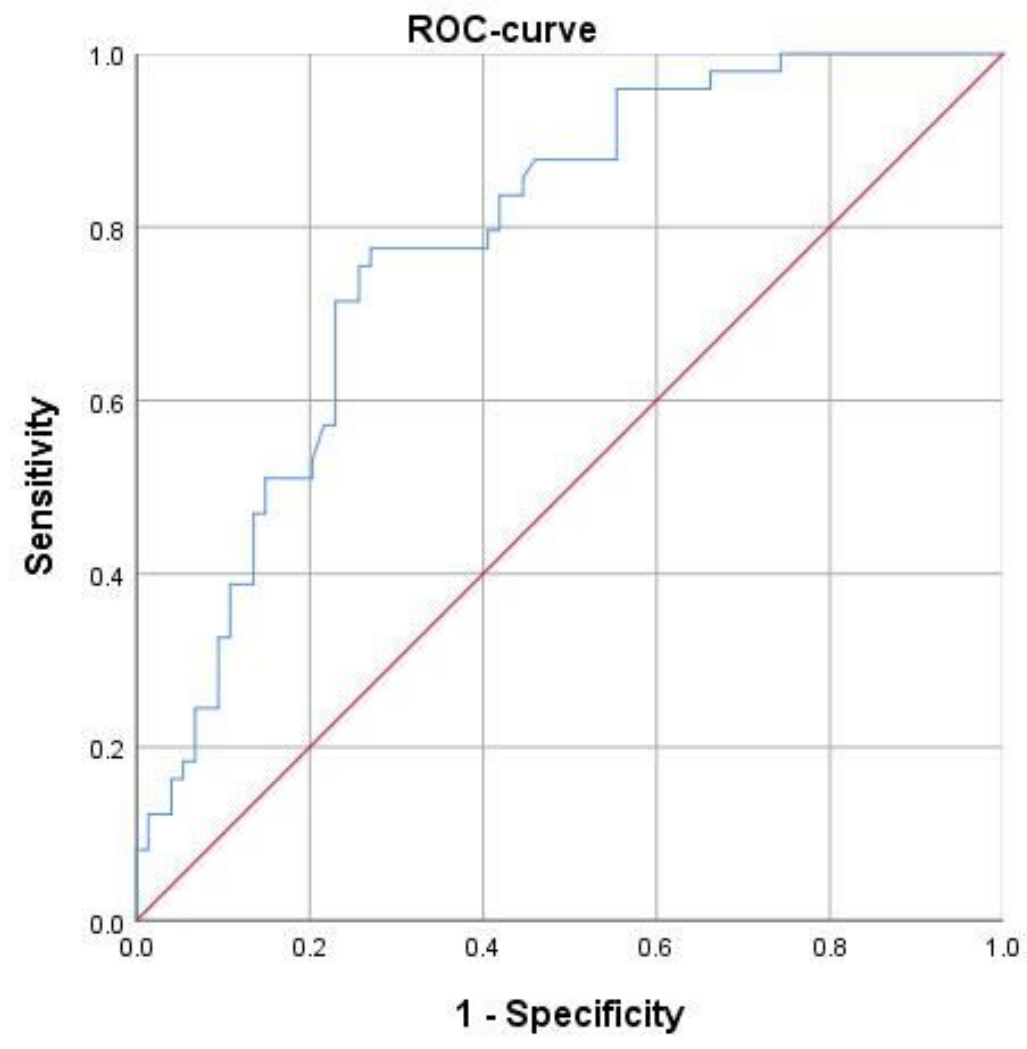

\section{Figure 3}

Receiver operating characteristic (ROC) curve for use of Ktrans for distinguishing of carcinomas with high proliferation potential (Ki67 >25\%) from tumors with low Ki 67 level $(<25 \%)$. The area under the curve is 0.78 . The optimal threshold value is 0.3 min- 1 yealding a sensitivity of $75.5 \%$, a specificity of $73.0 \%$, an accuracy of $74.0 \%$. The positive predictive value is $64.9 \%$, and the negative predictive value is $81.8 \%$. 


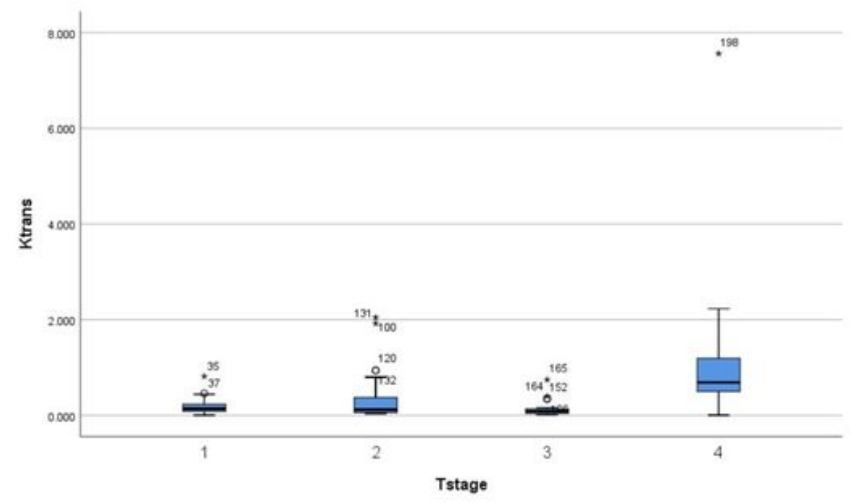

$4 a$

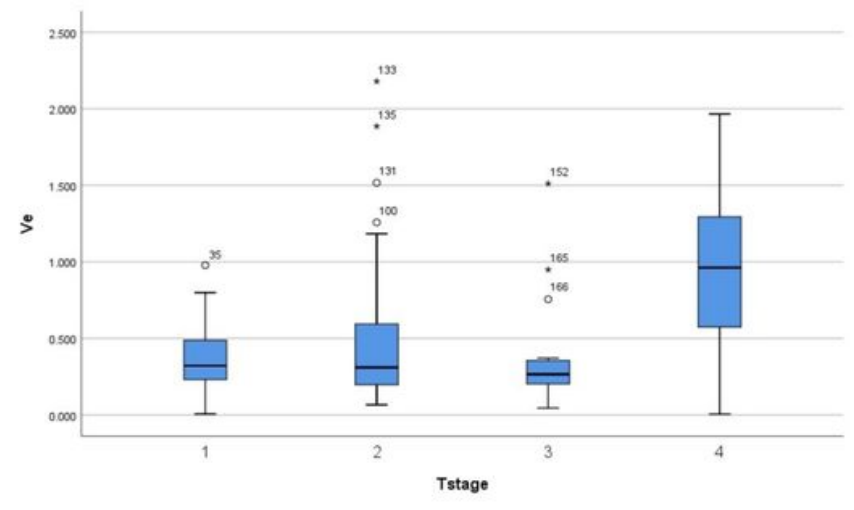

$4 b$

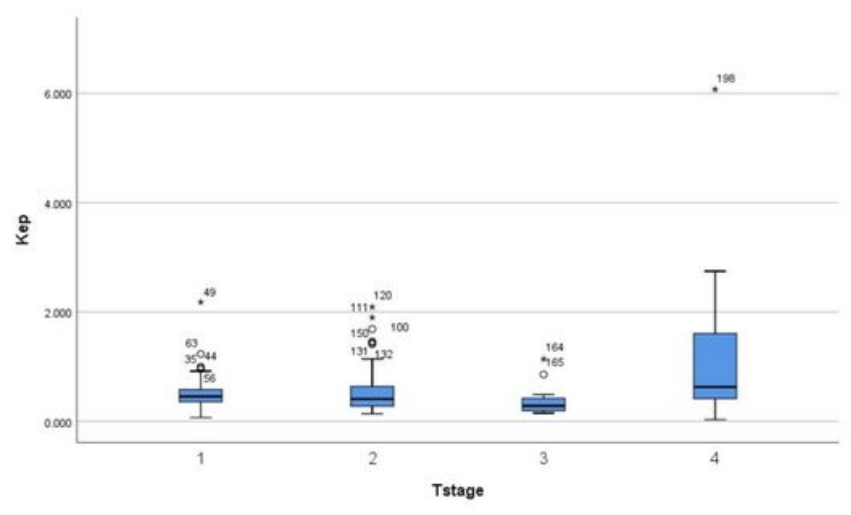

4c

\section{Figure 4}

Box plots of DCE MRI values in carcinomas with different tumor stages. a. Ktrans b. Ve c. Kep 


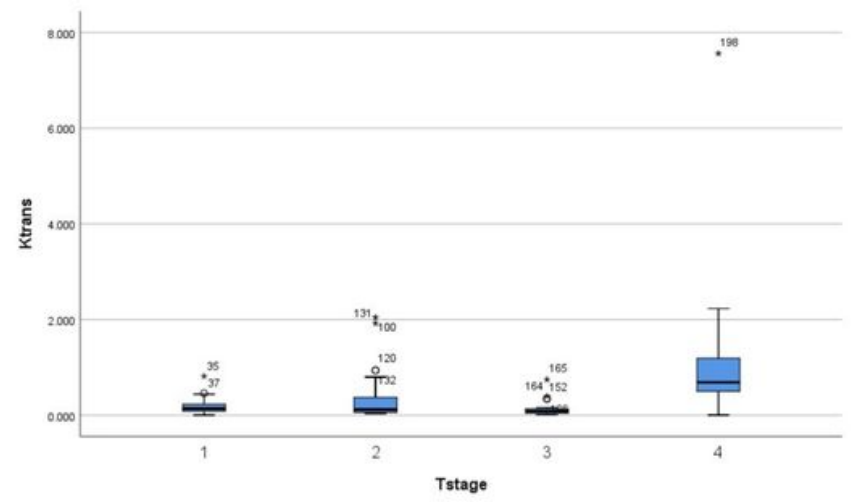

$4 a$

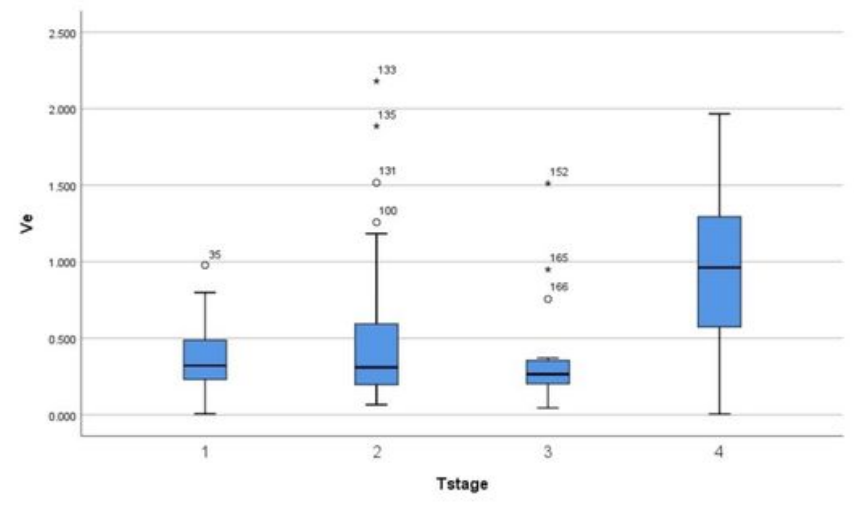

$4 \mathrm{~b}$

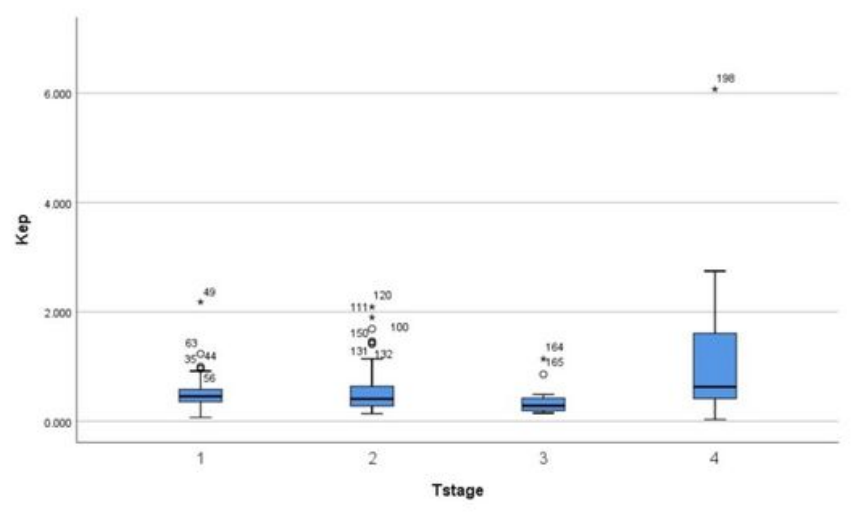

$4 c$

\section{Figure 4}

Box plots of DCE MRI values in carcinomas with different tumor stages. a. Ktrans b. Ve c. Kep 


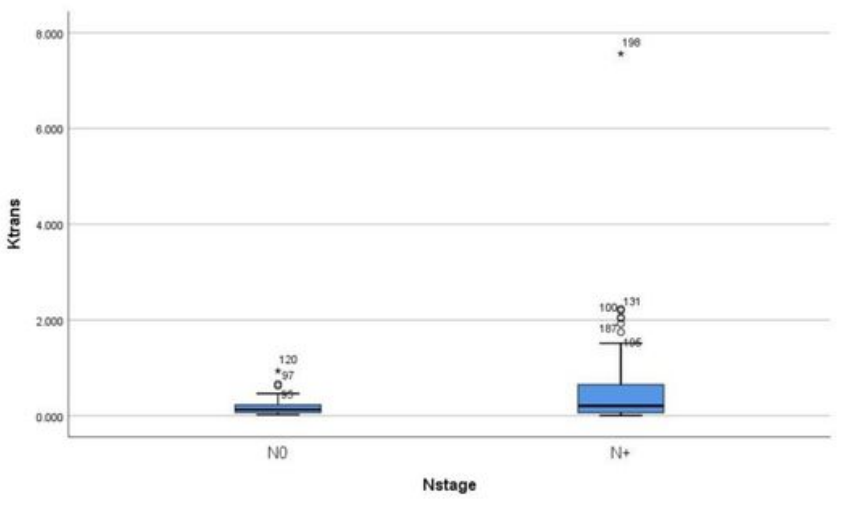

$5 a$

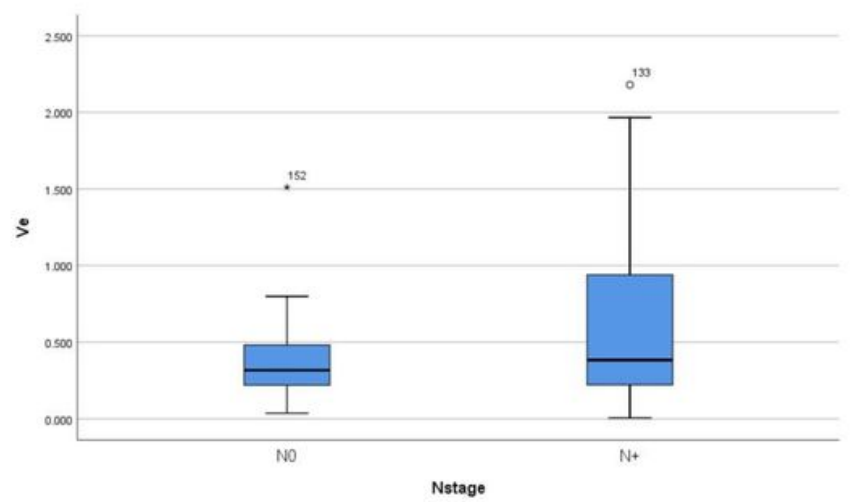

$5 b$

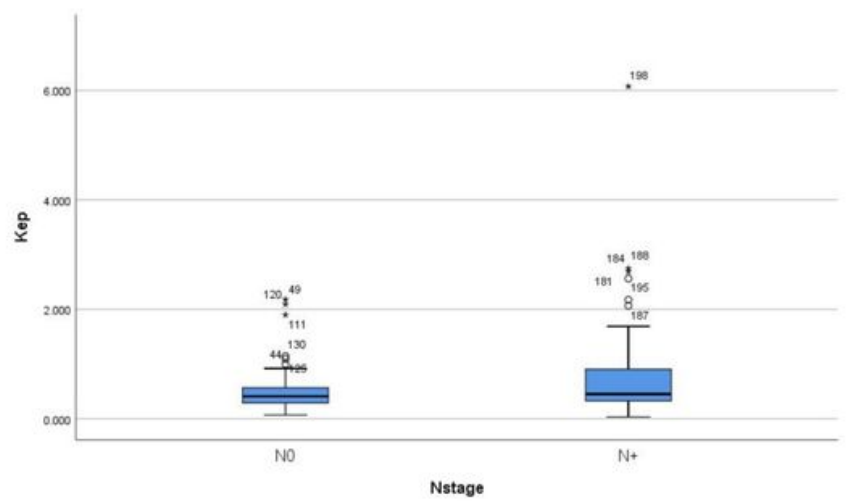

$5 c$

\section{Figure 5}

Box plots of DCE MRI values in carcinomas with different nodal stages. a. Ktrans b. Ve c. Kep 


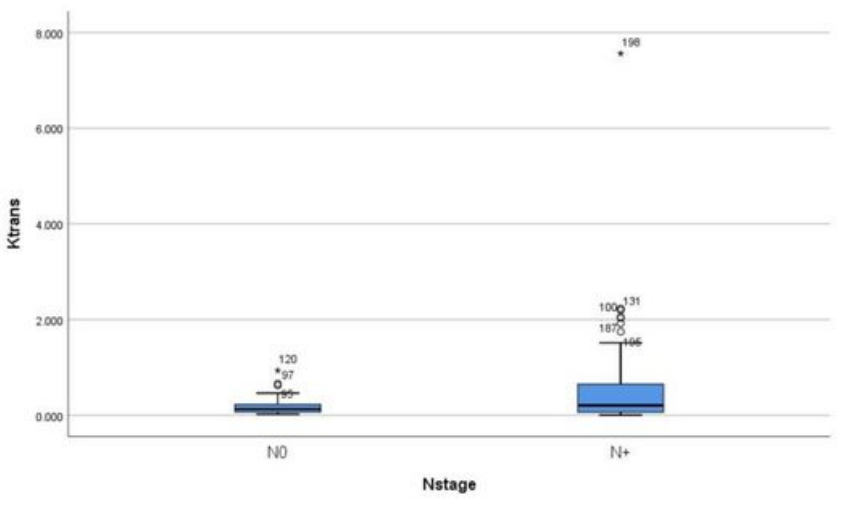

$5 a$

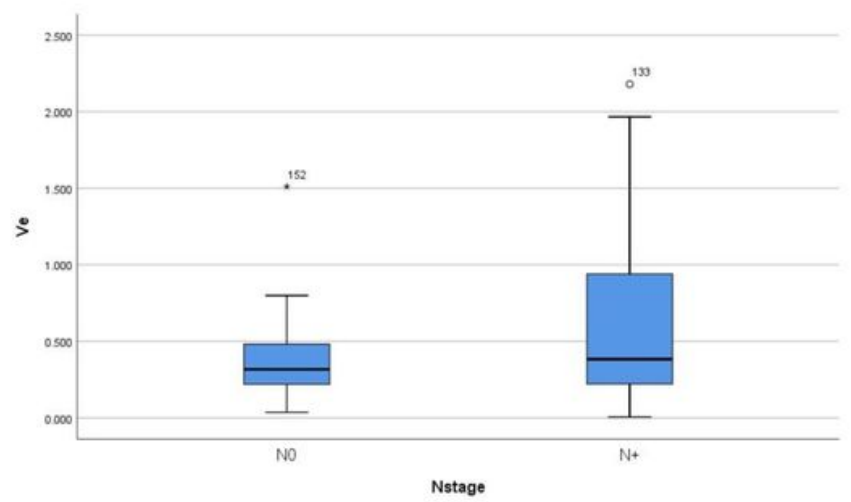

$5 b$

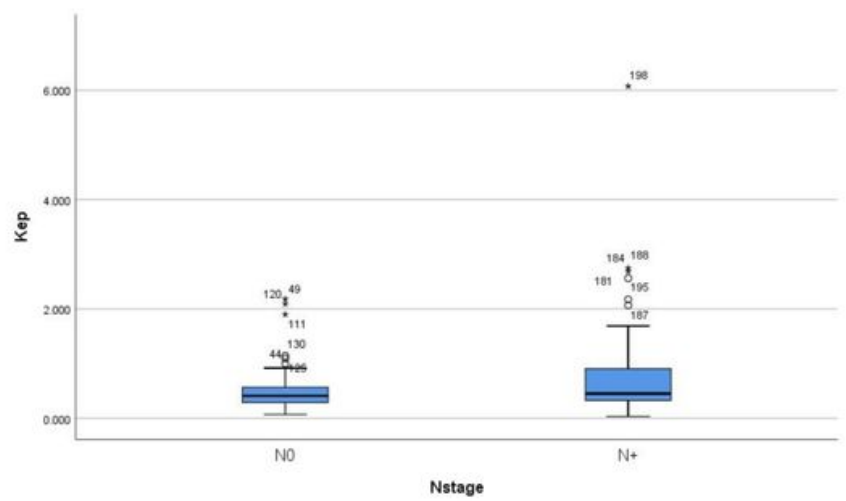

$5 c$

\section{Figure 5}

Box plots of DCE MRI values in carcinomas with different nodal stages. a. Ktrans b. Ve c. Kep 

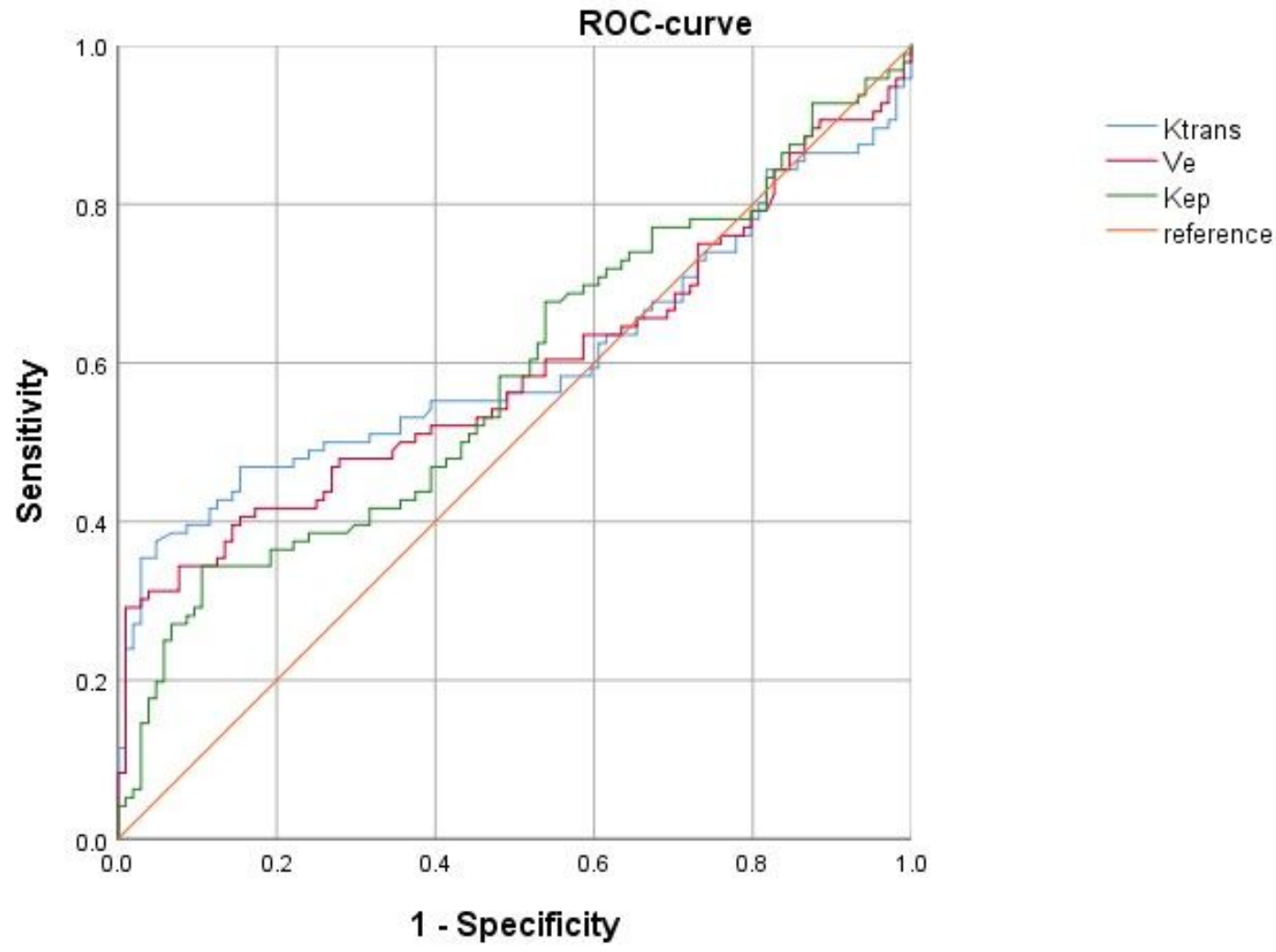

\section{Figure 6}

Receiver operating characteristic (ROC) curve for use of DCE MRI values for distinguishing of carcinomas with and without nodal metastases. The areas under the curve fort he parameters are as follows: Ktrans, 0.60; Ve, 0.59; Kep, 0.58 . 

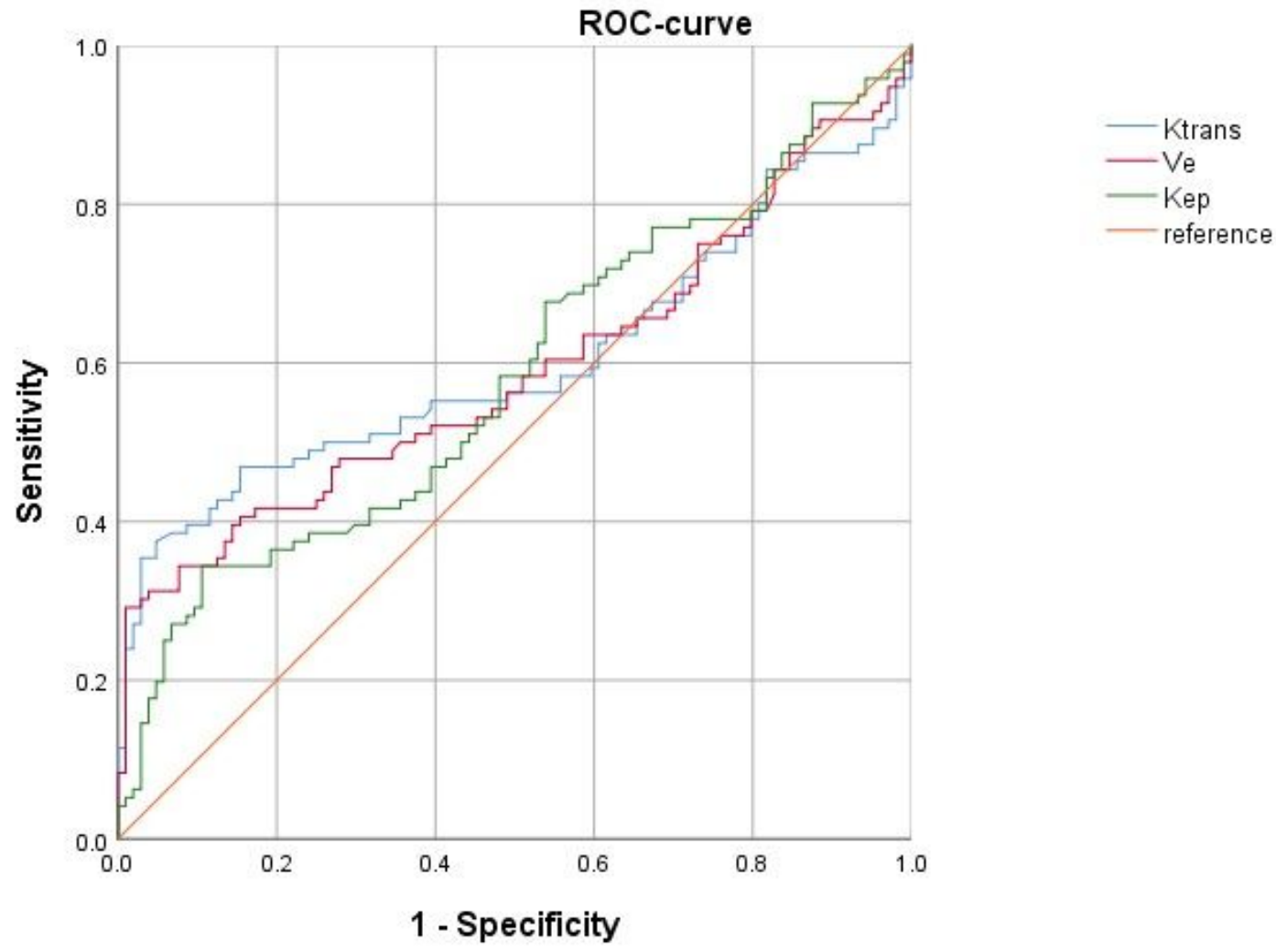

\section{Figure 6}

Receiver operating characteristic (ROC) curve for use of DCE MRI values for distinguishing of carcinomas with and without nodal metastases. The areas under the curve fort he parameters are as follows: Ktrans, 0.60; Ve, 0.59; Kep, 0.58 . 